themselves in the month after childbirth and did so by violent means suggests that many of them were psychotic.

Suicide is always a tragic event, particularly if the victim is-like Shakespeare's Lucretia or Ibsen's Hedda Gabler-a young woman with an unborn or newborn child. We can be thankful that suicides of this kind are now so rare. We can also derive some satisfaction from our ability to make sense of the trends and relations we observe.

R E KENDELL

Professor of Psychiatry,

Royal Edinburgh Hospital,

Edinburgh EH $105 \mathrm{HF}$
1 Robins E, Murphy G, Wilkinson RH, Gassner S, Kayes J. Some clinical considerations in the prevention of suicide based on a study of 124 successful suicides. Am f Public Health 1959;49: $888-99$

2 Barraclough B, Bunch J, Nelson B, Sainsbury P. A hundred cases of suicide: clinical aspects. $B r \mathcal{F}$ sychiatry 1974;125:355-73.

3 Appleby L. Suicide during pregnancy and in the first postnatal year. BM $1991 ; 302: 137-40$.

Barno A. Criminal abortion deaths, illegitimate pregnancy deaths, and suicides in pregnancy, Minnesota 1950-1965. Am f Obstet Gynecol 1967;98:356-67.

Kleiner GJ, Greston WM. Overview of demographic and statistical factors. In: Kleiner GJ, Greston WM, eds. Suicide in pregnancy. Boston: John Wright, 1984.

6 Weir JG. Suicide during pregnancy in London 1943-62. In: Kleiner GJ, Greston WM, eds. Suicide in pregnancy. Boston: John Wright, 1984.

Durkheim E. Le suicide. Spaulding JA, Simpson G, transl. New York: Free Press, 1951.

8 Otto U. Suicidal attempts made by pregnant women under 21 years. Acta Paedopsychiatrica 1965;32:276-88.

9 Kendell RE, Chalmers JC, Platz C. Epidemiology of puerperal psychoses. Br $\mathcal{F}$ Psychiatry 1987;150:662-73.

\title{
Ovarian hyperstimulation: actual and theoretical risks
}

\author{
Minimise them by monitoring oestrogen concentration
}

Treatments for infertility that entail superovulation (the production of several mature ovarian follicles) carry a small risk of the ovarian hyperstimulation syndrome. This has been recognised since the early use of gonadotrophins to induce ovulation: by 1961, 60 cases (including two deaths) had been reported after treatment with gonadotrophin from the serum of pregnant mares. By 1967 the syndrome had been classified into six grades of ascending severity, ranging from mild (clinically undetectable and diagnosed by a urinary oestrogen excretion greater than $150 \mu \mathrm{g} / 24 \mathrm{~h}$ ) through moderate (enlarged ovaries presenting with abdominal distension and vomiting) to the most severe (fluid shifts leading to ascites, haemoconcentration, and abnormalities of coagulation). ${ }^{1}$

After an association between the syndrome and increased oestrogen excretion was recognised Karam et al reduced its incidence by monitoring oestrogen concentrations. ${ }^{2}$ Using ultrasonography to monitor treatment led to an apparent increase in the milder grades of the syndrome (regarded as clinically unimportant $)^{3}$ but a decrease in the more severe grades. ${ }^{4}$

A recent study reported that the hyperstimulation syndrome occurred in $3 \%$ of cycles when human menopausal gonadotrophin was used. ${ }^{5}$ These cycles were associated with raised serum concentrations of oestradiol and prolactin, with many small follicles present at the end of stimulation. Patients at risk were young and thin and had received small doses of gonadotrophin. Increased concentrations of progesterone, oestrone, 17-hydroxyprogesterone, testosterone, and $\Delta^{5}$ steroids were found in their serum ${ }^{1}$; these are the steroids whose concentrations are raised in normal pregnancy.

The syndrome is explained by a sudden increase in capillary permeability, especially of the ovarian vessels, which results in ovarian stromal oedema and a shift of body fluid, increasing blood viscosity. Why increased permeability occurs is unknown but it may result from prostaglandins whose synthesis has been stimulated by excess oestrogens. Renin may also have a role: produced by ovarian thecal cells it is present in increased amounts in hyperstimulated ovulatory cycles when compared with normal cycles. ${ }^{6}$ Renin activity reaches a higher mid-luteal peak in those cycles in which the syndrome occurs, and the size of this peak correlates with the severity of the syndrome. ${ }^{7}$ The association may be explained by the angiogenetic properties of the renin-angiotensin system-this angiogenesis is associated with increased capillary permeability.
The ovarian hyperstimulation syndrome should be preventable by carefully monitoring treatment cycles and keeping the oestrogen concentration to the minimum that is effective. This may be achieved by daily measurement of the total oestrogen excretion, serum oestradiol, or early morning urinary oestrogen to creatinine ratio. ${ }^{8}$ At the same time follicular development should be followed by ultrasonography. Gonadotrophins should be withheld or stopped if the oestrogen concentrations exceed a predetermined limit or excess multiple follicles are present. If follicular stimulation is part of a programme of assisted reproduction then further intervention-such as aspirating the follicle-is possible.

How should the hyperstimulation syndrome be managed? In mild and moderate cases simple observation of the patient is sufficient. Severe cases require prompt treatment, mainly by correcting fluid and electrolyte imbalance. Anticoagulation may be necessary, and aspiration of fluid from pleural and peritoneal cavities under ultrasonographic control has been recommended. Indomethacin may be useful (presumably because of its effect on prostaglandin synthesis). ${ }^{1}$ Inhibiting prostaglandin synthesis could, however, lead to renal failure as renal perfusion in the presence of high renin activity is preserved by the simultaneous release of vasodilatory prostaglandins. ${ }^{9}$ Laparotomy should be avoided when possible as attempted removal of the cyst may lead to massive haemorrhage. Removal may be necessary, however, when there is torsion of an ovarian cyst or intraperitoneal haemorrhage due to rupture. In these cases surgery should be as limited as possible to minimise risks and preserve precious gonadal tissue.

Could hyperstimulation increase the risk of ovarian cancer as has been recently suggested ${ }^{1011}$ Proving an association between the two will be difficult because of the likely rarity of the complication and the long time that may elapse between treatment and the clinical appearance of cancer. A retrospective case-control study would therefore answer the question sooner than a long term cohort study. Index cases might come from two sources: cases of the ovarian hyperstimulation syndrome notified to the recently created Human Fertilisation and Embryology Authority or cases of the syndrome reported as "adverse drug reactions" to the Committee on Safety of Medicines. Both would require a high level of cooperation from doctors.

Currently the risk of cancer is unproved. The risk of the hyperstimulation syndrome after superovulation is well estab- 
lished: keeping oestrogen concentration to the lowest that is effective minimises that risk.

BLAIR H SMITH

Senior House Officer,

Department of Obstetrics and Gynaecology,

Northern General Hospital,

Sheffield S5 7AU

Professor of Obstetrics and Gynaecology,

Jessop Hospital for Women,

Sheffield S3 7RE

1 Schenker JG, Weinstein D. Ovarian hyperstimulation syndrome: a current survey. Fertil Ster 1978;30:255-68.

2 Karam KS, Taymor ML, Berger MJ. Estrogen monitoring and the prevention of ovarian overstimulation during gonadotrophin therapy. Am f Obstet Gynecol 1973;115:972-7.
3 McArdle C, Seibel M, Hann LE, Weinstein F, Taymor M. The diagnosis of ovarian hyperstimulation syndrome (OHS): the impact of ultrasound. Fertil Steril 1983;39:464-7.

Diamond MP, Wentz AC. Ovulation induction with human menopausal gonadotrophins. Obste Gynecol Surv 1986;41:480-90.

5 Navot D, Relou A, Birkenfield A, Rabinowitz R, Brzezinski A, Margalioth EJ. Risk factors and prognostic variables in the ovarian hyperstimulation syndrome. Am $\mathcal{F}$ Obstet Gynecol 1988;159: progn $210-5$

6 Paulson RJ, Do YS, Hsueh WA, Eggena P, Lobo TA. Ovarian renin production in vitro and in vivo: characterisation and clinical correlation. Fertil Steril 1989;51:634-8.

IAN D COOKE 7 Navot D, Margalioth EH, Laufer N, et al. Direct correlation between plasma renin activity and severity of the ovarian hyperstimulation syndrome. Fertil Steril 1987;48:57-61.

8 Tang GW, Chan SY. Further evaluation of first morning urinary oestrogens in monitoring gonadotrophin therapy. Aust N Z J Obstet Gynaecol 1988;28:141-3.

9 Balasch J, Carmona F, Llach J, Arroyo V, Jove I, Vanrell J. Acute prerenal failure and liver dysfunction in a patient with severe ovarian hyperstimulation syndrome (case report). Hum Reprod 1990;5:348-51.

10 Fishel S, Jackson P. Follicular stimulation for high tech pregnancies: Are we playing it safe? $B M$ 1989;299:309-11.

11 Cruikshank DJ. Aetiological importance of ovulation in epithelial ovarian cancer. BMf 1990;301 $524-5$

\section{Leptospirosis update}

\section{The risk is small and may be reduced by simple precautions}

Leptospirosis has recently been the subject of increased media attention, prompting confusion and anxiety among several groups who have not previously seen themselves as being at risk-such as canoeists and other recreational water users. What are the risks of contracting the disease, how dangerous is it, and can those at risk do anything to protect themselves?

The genus leptospira comprises two species: Leptospira biflexa, which includes saprophytic serovars (serotypes), and $L$ interrogans, which contains 202 pathogenic serovars in 23 serogroups. ${ }^{1}$ In the British Isles pathogenic leptospires from 10 serogroups have been isolated from wild and domestic animals. Infected animals usually remain well but excrete large numbers of organisms into the environment. Leptospires survive in moist conditions outside the host for many days (except in salt water, where they survive only a few hours) but are easily destroyed by drying, exposure to disinfectants and detergents, and heating to $50^{\circ} \mathrm{C}$ for five minutes. Humans become infected through contact with the urine or tissues of infected animals or through contact with water that harbours leptospires. Bacteria enter through skin cuts and abrasions or through the mucous membranes of the eyes or nasopharynx.

Leptospirosis presents in various ways, from inapparent to fulminating and fatal infection. After a seven to 12 day incubation period the disease has two overlapping phases, the first characterised by leptospiraemia and the second by leptospiruria and rising antibody titres. Turner's view in 1969 that "laboratory investigations will rarely help the patient because they can seldom confirm the diagnosis in time to influence treatment" remains true today. ${ }^{2}$ About $90 \%$ of symptomatic patients present with a mild influenza-like illness which usually resolves uneventfully in two to three weeks. Occasionally patients present with lymphocytic meningitis. Only a small proportion develop haemorrhagic complications and severe kidney and liver failure (Weil's disease), and only $10-20 \%$ of these patients die from myocarditis, haemorrhage, or multiorgan failure. Death without jaundice is virtually unknown, and chronic infection with persistent leptospiruria or uveitis is rare.

Leptospirosis is confirmed either by isolating the organism or, more commonly, by detecting specific antibodies in the patient's blood at the end of the first week of illness. Serological testing for leptospirosis is appropriate only for confirming an initial clinical suspicion and not for deciding whether or not to start treatment. Antibiotic treatment is controversial, and many people recover without treatment.

\section{Reducing the risk of leptospirosis}

- Eliminate rats and don't touch them with unprotected hands

- Cover all cuts with waterproof plasters and wear protective clothing

- Avoid immersion in natural waters

- Wear footwear

- Shower after canoeing, windsurfing, waterskiing, or swimming

Controlled trials suggest benefit by giving antibiotics within the first four days of illness-before the diagnosis can be confirmed. Severe cases need supportive care, and penicillin $1.5 \mathrm{MU}$ or ampicillin $1 \mathrm{~g}$ may be given parenterally every six hours. ${ }^{3}$ Alternatively, erythromycin $250 \mathrm{mg}$ every six hours or tetracycline $250 \mathrm{mg}$ every eight hours can be given to patients hypersensitive to penicillin.

Traditionally leptospirosis was associated with sewermen, miners, and fish workers, but farmers and agricultural workers are now the main occupational group at risk, accounting for $52 \%$ of cases. People in contact with rats or natural inland waters are potentially at risk-although this is small, and the data are inadequate to confirm whether recreational water users are at increased risk. Of the 299 confirmed cases in England and Wales during 1985-9, 268 occurred in the working age group 15-64 and 21 occurred in women. The disease has a well defined seasonal pattern with most cases occurring from July to December.

Leptospirosis due to $L$ sejroe serovar hardjo from cattle accounted for 157 of cases, $L$ icterohaemorrhagiae for 87 , undetermined serovars for 45 , and other serovars for 10 . The absence of human $L$ canicola infection since 1985 may be attributed to canine immunisation. Interestingly, six cases of $L$ sejroe serovar saxkoebing, which has recently been detected in cattle, were confirmed, with three cases related to water contact. During the five years there were 15 deaths, 11 due to $L$ icterohaemorrhagiae and four to undetermined strains (PHLS Communicable Disease Surveillance Centre, unpublished data). The Leptospira Reference Laboratory confirmed 44 cases from Scotland with one fatality, 42 cases from Ireland with four fatalities, and 92 cases acquired abroad during the same period.

Total prevention or eradication of leptospires (and hence absolute prevention of leptospirosis) is impossible. Large 